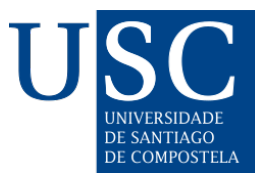

REVISTA INTERNACIONAL de

COMUNICACIÓN y DESARROLLO

Revista Internacional de Comunicación y Desarrollo (RICD), 4(15), 2021. ISSN-e: 2386-3730

https://doi.org/10.15304/ricd.4.15.8178

Conversaciones

\title{
Ciudades visibles, ciudades invisibles
}

Visible cities, invisible cities

Anna Clua

Universitat Oberta de Catalunya, España

acluai@uoc.edu

El desarrollo de las ciudades como ecosistemas complejos en un contexto en cambio constante y su crecimiento exponencial vinculado al valor económico nos sitúa ante el reto de su sostenibilidad. ¿Cuál es (si lo hay) el límite a ese desarrollo? La agenda de acciones de la ONU alrededor de los Objetivos de Desarrollo Sostenible en relación a las ciudades (ODS número 11) apunta claramente a la idea de poner freno a la contaminación medioambiental, así como a reconocer el problema del crecimiento desequilibrado de las ciudades a escala global, o el crecimiento de los márgenes y marginalidades urbanas, así como el aumento de las desigualdades a la hora de ejercer el derecho a la ciudad. El actual contexto de crisis pandémica ha comportado añadir, además, la necesidad de incorporar el concepto de "ciudades cuidadoras" a los modelos de gestión urbana. De este modo, los valores de la solidaridad, la corresponsabilidad y la ayuda mutua emergen como lugares comunes de visita obligada en la ciudad sostenible. No obstante, éstos no son conceptos nuevos con los que definir la ciudad futura. Históricamente, no han faltado personas ni colectivos trabajando en pos de la justicia espacial y social desde el punto de vista del apoyo mutuo. Por ejemplo, no podríamos hablar del Manifiesto de los Cuidados (Chatzidakis et al., 2020) sin hablar primero de la obra de Piotr Kropotkin (1902). Ya hace tiempo que sabemos que la ciudad gobernada y la ciudad donde la vida es posible no pueden andar separadas, pero quizás no nos habíamos dado cuenta de que el reto consiste en mantenerlas en diálogo.

La conversación entre Silvia Cepero y David Fernández nos da pistas sobre lo urgente que es revisitar la ciudad desde ese diálogo. Cepero y Fernández son dos profesionales de la comunicación audiovisual cuyo denominador común es el haber trabajado en proyectos de comunicación audiovisual participativa desde la ciudad (concretamente, desde Barcelona), abordando tanto la articulación y visibilización de narrativas no hegemónicas, como la creación artística con capacidad y capacitación emancipadora. Si bien sus trayectorias y sus posicionamientos los sitúan ante distintas formas de entender el papel de la comunicación en la ciudad, hay ideas que ambos comparten. La idea en la que ambos coinciden de forma más evidente es la reivindicación de los proyectos comunicativos participativos en tanto que procesos. La comunicación audiovisual así entendida no es un medio para la consecución de un fin. El proceso al que da pie un proyecto participativo no es un proceso lineal con la mirada puesta en un resultado concreto. De ahí que la práctica de la comunicación audiovisual como mera herramienta para alcanzar una "ciudad 
sostenible" tenga pocas posibilidades de ir más allá de la etiqueta para provocar una transformación real.

Las políticas desplegadas alrededor de una agenda de objetivos, como los ODS, corren el riesgo de limitarse a reproducir la lógica del "check", convirtiendo los resultados de todo proyecto en fines en sí mismos que hay que validar para justificar el éxito de una acción planificada. Sin embargo, es difícil que este tipo de acciones tengan un efecto a medio o largo plazo, más allá de los tiempos de ejecución de los programas, los planes o las estrategias para desplegar la sostenibilidad urbana. Esta lógica tan instaurada en las instituciones, en las empresas e incluso en las universidades, responde a unos ritmos que no son acordes a la cantidad y calidad de tiempo que requiere un cambio en las dinámicas sistémicas, ni mucho menos permite garantizar que los proyectos desarrollados den pie a una transformación real de las estructuras que rigen las relaciones de poder (y de poder hablar) en la ciudad.

Silvia Cepero y David Fernández exponen la importancia de que la participación comunicativa no sea una invitación que llega desde arriba, sino una forma de ejercer un derecho que adquiere consistencia colectiva en el momento en que se convierte en consciencia. El hecho de experimentar y poner a la práctica la creación audiovisual permite ese darse cuenta de que existen herramientas, lenguajes y narrativas con las que explicar lo que le pasa a la ciudad y lo que les pasa a las personas en la ciudad. Es como adquirir la capacidad de descubrir que ante la realidad siempre se superponen capas de discursos que algunas veces pueden reconocer la diversidad y el conflicto, pero que mayoritariamente ofrecen una versión compacta que más bien uniformiza.

Siguiendo este razonamiento, ponerle a la ciudad la etiqueta de "sostenible" implica obviar lo que para muchas personas puede resultar insostenible en su día a día, desde el hecho básico de carecer de papeles hasta el precio del alquiler de una vivienda, pasando por el coste personal del trabajo cuando éste no va de la mano de derechos laborales reconocidos o cuando, precisamente por ello, se persigue y se multa a quien pretende sobrevivir con ello. ¿Dónde están las personas que viven en los márgenes de los márgenes? Silvia Cepero cuenta que no las ve en los procesos participativos. David Fernández dice, simplemente, que no están: han sido expulsadas de los barrios (como ha ocurrido en el22@ que han adquirido nueva centralidad tras el cambio de modelo económico. ¿Cabe hablar de la ciudad sostenible si ésta no funciona como sostén de los derechos fundamentales ni del propio derecho a la ciudad?

Ante la ciudad que habla tenemos que preguntarnos por la ciudad que escucha. Si no hay espacios de escucha atenta, sino solamente escaparates donde se anuncia la urbe modélica, ¿qué responsabilidad cabe exigir a la creación audiovisual?, ¿qué discursos sobre ciudad acaba imponiéndose? Tanto Silvia Cepero como David Fernández hablan de la importancia de no fijar las expectativas en la pieza resultante de un proceso colectivo de creación audiovisual. Los dos han vivido de primera mano la importancia que el proceso mismo tiene para las personas participantes. Fernández, además, es pesimista respecto a la utilidad que la pieza resultante pueda tener una vez finalizado el proceso de creación. Para él, el hecho de que la pieza acabe siendo descontextualizada y exhibida cual rareza exótica o producto de consumo hace que ésta se vea desprovista de su valor cultural y de su capacidad transformadora.

La pregunta que surge tras todo lo expuesto no es qué tipo de sostenibilidad sino por qué tipo de comunicación hablan las ciudades cuyos barrios se encuentran cada vez más amenazados por la invisibilización de ciertos colectivos y por la ruptura de los vínculos sociales que los constituyen. Para responder a esta pregunta debemos revisitar críticamente la forma en que ha sido tradicionalmente conceptualizada la centralidad de la acción comunicativa. La ingente obra de 
Jürgen Habermas ha permitido sentar las bases de un prolífico debate teórico alrededor de la praxis comunicativa como punto de partida para explicar fenómenos como la integración social y sistémica (Habermas [1981] 1987). Pero la visión normativa de Habermas (que explica la configuración de la esfera pública desde la racionalidad del consenso normativo) ha sido cuestionada desde otras perspectivas que optan por definir la esfera pública como un espacio de conflicto, donde las acciones que no forman parte del discurso hegemónico tienen también sus espacios de expresión (Mouffe, 2011). Es en esta "otra” esfera pública (o esferas públicas) donde se reconoce la coexistencia de distintas voces que luchan por su supervivencia, incluyendo aquellas que habitan espacios no visibles.

La situación de pandemia ha evidenciado los problemas que se derivan de la desconexión social en la ciudad. Por un lado, se han hecho palpables los problemas derivados de la existencia previa de espacios vetados (por ejemplo, aquellos espacios regulados por las leyes y ordenanzas que gestionan el uso del espacio público o que definen el concepto mismo de ciudadanía). Por otro lado, la situación se ha agravado a partir del momento en que los usos de los espacios de sociabilidad habituales se han visto modificados por protocolos y normas de seguridad.

En este contexto las redes de comunicación han adquirido una gran relevancia, por su actual arraigo en la esfera de la vida cotidiana y como espacios donde tiene cabida las relaciones afectivas. El estar "conectados" ha resultado ser vital para los colectivos más precarizados, la supervivencia de los cuales dependía de su conexión con el entorno inmediato. Estas redes han incluido efectivamente la posibilidad de apoyo mutuo en aspectos básicos como el acceso al alimento diario o a un techo. También han permitido los cuidados, la comunicación con vecinos o familiares, así como la información o puesta en conocimiento de situaciones de riesgo.

La vivencia de una situación extrema como el confinamiento decretado durante el estado de alarma por COVID-19 ha puesto en evidencia la importancia de los procesos comunicativos de base, en tanto que prácticas de supervivencia. Es en este contexto que se ha generado conocimiento empírico sobre la acción comunicativa, permitiendo replantear el fenómeno de la conexión/ desconexión social del que hablaban Couldry, Livingstone y Markham (2007), poniéndolo en relación con la constitución de redes de apoyo mutuo que no forman parte de ninguna planificación institucional, sino que surgen de la necesidad de quienes viven y luchan por seguir viviendo en la ciudad. Esta situación ha permitido también dar cuenta de aspectos importantes que hasta ahora no se tenían en cuenta al hablar de comunicación y ciudad, como lo son el papel de las emociones en la construcción de lazos de conexión y solidaridad, así como del papel de las mujeres en la construcción de las redes de apoyo. Puede que, a partir de este contexto, la pregunta sobre el papel de la comunicación audiovisual en la ciudad abra nuevas perspectivas de interpretación. No estaremos hablando solamente de procesos participativos ni de vídeos colaborativos, sino de nuevas maneras colectivas de expresar y transmitir (en un clic reticular) la urgencia y la emergencia de reivindicar el derecho a la ciudad.

\section{REFERENCIAS BIBLIOGRÁFICAS}

Chatzidakis, A., Hakim, J. Litter, J. \& Rottenberg, C. (2020). The care manifesto: The politics of interdependence. Verso Books.

Couldry, N., Livingstone, S., \& Markham, T. (2007). Connection or Disconnection?: Tracking the Mediated Public Sphere in Everyday Life. In Butsch, R. (ed.), Media and Public Spheres (pp. 28-42). Palgrave Macmillan. 
Habermas, J. (1987). Teoría de la acción comunicativa, I. Racionalidad de la acción y racionalización social.

Taurus. (Original publicado en 1981).

Kropotkin, P. (1902). Mutual Aid: A Factor of Evolution. McClure Phillips \& Co.

Mouffe, C. (2011). On the political. Routledge

NOTAS

Anna Clua es profesora del área de estudios de Ciencias de la Información y de la Comunicación en la Universitat Oberta de Catalunya (UOC). Doctora en Ciencias de la Información por UAB se ha especializado en Teorías de la Comunicación y en la geografía cultural y urbana.

Contacto: acluai@uoc.edu 